\title{
Activation of COX-2/mPGES-1/PGE2 Cascade via NLRP3 Inflammasome Contributes to Albumin-Induced Proximal Tubule Cell Injury
}

\author{
Yibo Zhuang a,b,c Fei Zhao ${ }^{a, b, c}$ Jing Liang ${ }^{a, b, c}$ Xu Deng ${ }^{a, b, c}$ Yue Zhanga, ${ }^{a, b, c}$ \\ Guixia Ding ${ }^{a, b, c}$ Aihua Zhang ${ }^{a, b, c}$ Zhanjun Jia $a^{a, b, c}$ Songming Huang ${ }^{a, b, c}$ \\ aDepartment of Nephrology, Children's Hospital of Nanjing Medical University, Nanjing, bJiangsu Key \\ Laboratory of Pediatrics, Nanjing Medical University, Nanjing, 'Nanjing Key Laboratory of Pediatrics, \\ Children's Hospital of Nanjing Medical University, Nanjing, China
}

\section{Key Words}

Albumin • NLRP3 inflammasome $•$ COX-2 $•$ PGE2 $•$ Proximal tubule cells

\begin{abstract}
Background/Aims: The activation of NOD-like receptor family, pyrin domain containing3 (NLRP3) inflammasome has been shown to be positively correlated with the severity of proteinuria in chronic kidney disease (CKD) patients. Prostaglandin E2 (PGE2), an important inflammatory mediator, is also involved in various kidney injuries. The aim of the present study was to investigate the involvement of NLRP3 inflammasome and PGE2 synthetic pathway in albumin-induced renal tubular injury. Methods: Murine proximal tubular cells (mPTCs) were treated with albumin to induce cell injury. NLRP3 siRNA and specific COX-2 inhibitor NS398 were used to define their roles in mediating albumin-induced MPTC injury or the activation of COX-2/mPGES-1/PGE2 cascade. Results: In mPCTs, inhibition of NLRP3 by a small interfering RNA (siRNA) blocked albumin-induced kidney injury molecule 1 (KIM-1) upregulation, inflammatory response, and cell apoptosis. Albumin markedly activated cyclooxygenase-2 (COX-2)/ microsomal prostaglandin E synthase-1 (mPGES-1)/PGE2 pathway in this cell line, an effect largely abolished by NLRP3 silencing at both mRNA and protein levels. More interestingly, blockade of COX-2 using a specific COX-2 inhibitor NS398 markedly inhibited the upregulation of KIM-1 and inflammatory cytokines, and attenuated cell apoptosis in line with blunted PGE2 release following albumin treatment. Conclusions: The findings suggest that COX-2/mPGES-1/PGE2 axis could be activated by albumin in the proximal tubular cells via a NLRP3 inflammasome-mediated mechanism and could thus contribute to proteinuriarelated renal tubular cell injury.
\end{abstract}

Y. Zhuang, F. Zhao and J. Liang contributed equally this work. 


\section{Cellular Physiology \\ \begin{tabular}{ll|l} 
DOI: 10.1159/000478070 & $\begin{array}{l}\text { @ } 2017 \text { The Author(s). Published by S. Karger AG, Basel } \\
\text { www.karger.com/cpb }\end{array}$ \\
\cline { 2 - 4 }
\end{tabular}}

\section{Introduction}

Chronic kidney disease (CKD) is a kind of renal disease with progressive loss of renal function and structural damage caused by various primary and secondary insults over a period of months or years. In the past decades, the prevalence of CKDs is increasing with the rapid growth of hypertension, diabetes and other metabolic disorders [1]. Among the insults resulting in the CKD progression, proteinuria is proven as an independent risk factor [2]. Although a number of studies have been performed to explore the pathogenic mechanisms of proteinuria-mediated kidney injury, we still lack the effective target for the treatment of proteinuria-caused renal injury.

Recently, NOD-like receptor family, pyrin domain containing3 (NLRP3) inflammasome was characterized as a contributor of CKDs [3]. More interestingly, Fang et al. found that the activation of NLRP3 inflammasome was positively correlated with the severity of proteinuria in patients, and the NLRP3 inflammasome was directly activated by albumin in the cultured renal epithelial cells [4]. These findings highly suggested that NLRP3 might serve as an important pathogenic factor in mediating proteinuria-induced renal tubular damage. However, the mechanisms mediating the pathogenesis of NLRP3 inflammasome in proteinuria-induced renal tubular damage remains elusive. Recently, our group reported that COX-2/mPGES-1/PGE2 could be activated by NLRP3 inflammasome in thick ascending limb to downregulate NKCC2 under the proteinuric condition [5], while the role of this cascade in proteinuria-induced renal tubular cell injury was not defined.

Among five major prostaglandins (PGE2, PGD2, PGI2, PGF2 $\alpha$, and TXA2) produced in kidney [6], PGE2 has the established roles in mediating the fluid metabolism [7-10], and kidney injury [11-13]. PGE2 is generated through a sequential enzyme cascade of COX/PGE2 synthases (PGES) [14]. By now, two COXs (COX-1 and COX-2) and three PGESs (mPGES-1, mPGES-2, and cPGES) were cloned. COX-1 constitutively expressed in platelets, gastric epithelial cells, and renal collecting ducts and arteriolar endothelial cells, regulates blood pressure (BP) and renal hemodynamics $[15,16]$. COX-2 has low basal expression in various organs but is highly inducible by a number of pathological stimuli [15-17]. In kidney, COX-2 distribution has been localized in the macula densa, cortical thick ascending limb of Henle, and interstitial cells [18]. The stimulation of COX-2 in proximal tubules possibly contributes to renal injury $[17,19,20]$. Among three PGESs, mPGES-1 is best identified as a PGE2 synthetic enzyme [14, 21]. In contrast, genetic deletion of mPGES-2 and cPGES had no effect on lowering PGE2 levels in mice [22, 23], which argues their property of PGE2 synthases. Recently, a number of reports demonstrated that COX-2/mPGES-1/PGE2 cascade is of importance in promoting renal injury in CKD and AKI $[19,24]$. In the present study, we investigated: 1) whether albumin could activate COX/mPGES-1/PGE2 cascade in proximal tubular cells; 2) whether COX/mPGES-1/PGE2 cascade served as the downstream signaling of NLRP3 inflammasome in this pathological process; and 3) whether COX/mPGES-1/PGE2 cascade contributes to albumin-induced tubular cell injury.

\section{Materials and Methods}

\section{Cell culture studies}

Immortalized mouse proximal tubular cells (mPTCs) from Sciencell Research Laboratory (Cat \#: M4100) were cultured in serum-free keratinocyte medium supplemented with bovine pituitary extract, epidermal growth factor (Wisent, Canada), and penicillin/streptomycin at $37^{\circ} \mathrm{C}$ with $5 \% \mathrm{CO}_{2}$, and subcultured at $50-80 \%$ confluence using $0.25 \%$ trypsin- $0.02 \%$ EDTA (Invitrogen). Delipidated albumin (Sigma, St Louis, MO) was dissolved in the medium with no penicillin/streptomycin to stimulate mPTCs. In brief, albumin was firstly dissolved in culture medium at the concentration of $0.25 \mathrm{~g} / \mathrm{ml}$ which was further diluted to the final concentrations $(2.5,5,10$, and $20 \mathrm{mg} / \mathrm{ml})$ used in the experiments. The control cells were administered with same amount of culture medium. Because the dose-dependent experiment showed that 


\section{Cellular Physiology Cell Physiol Biochem 2017;42:797-807 \begin{tabular}{ll|l} 
and Biochemistry & $\begin{array}{l}\text { DOI: 10.1159/000478070 } \\
\text { Published online: June 19, } 2017\end{array}$ & $\begin{array}{l}\text { (c) } 2017 \text { The Author(s). Published by S. Karger AG, Basel } \\
\text { www.karger.com/cpb }\end{array}$
\end{tabular}

albumin at $10 \mathrm{mg} / \mathrm{ml}$ caused striking induction of tubular injury marker KIM-1, $10 \mathrm{mg} / \mathrm{ml}$ albumin was used in other experiments of the study.

\section{NIRP3 SiRNA transfection}

mPTCs were cultivated to $50-60 \%$ confluence in culture medium with no penicillin or streptomycin. SiNlrp3 and scrambled siRNA were synthesized by the company of GenePharma. Then the cells were transfected with siRNAs using Lipofectamine 2000 (Invitrogen) according to the manufacturer's instructions. In brief, the cells were transfected with $500 \mathrm{nM}$ NLRP3 siRNA or scrambled siRNA $24 \mathrm{~h}$ before albumin treatment. siNLRP3: 5'-CGGCCUUACUUCAAUCUGUTT-3', 5'-ACAGAUUGAAGUAAGGCCGTT-3'; scrambled siRNA: 5'-UUCUCCGAACGUGUCACGUTT-3', 5'-ACGUGACACGUUCGGAGAATT-3'.

\section{Quantitative real-time PCR ( $q R T$-PCR)}

Total RNA was extracted by using the TRIzol reagent (Invitrogen). Oligonucleotides were designed using Primer3 software (available at http://frodo.wi.mit.edu/) and synthesized by Invitrogen company. The sequences of the primer pairs are shown in Table 1. Reverse transcription was performed using a reaction kit (Promega Reverse Transcription System) according to the manufacturer's protocol. Real-time PCR amplification was performed using the ABI 7500 real-time PCR detection system (Foster City, CA, USA) with SYBR Green PCR Master Mix (Applied Biosystems). The cycling conditions were $95^{\circ} \mathrm{C}$ for $10 \mathrm{~min}$, followed by 40 cycles of $95^{\circ} \mathrm{C}$ for $15 \mathrm{~s}$ and $60^{\circ} \mathrm{C}$ for $1 \mathrm{~min}$. The mRNA levels were normalized to GAPDH as a control and calculated using the comparative cycle threshold $(\Delta \Delta \mathrm{Ct})$ method.

\section{Western blotting}

mPTCs were lysed using a protein lysis buffer containing $50 \mathrm{mM}$ Tris, $150 \mathrm{mM} \mathrm{NaCl}, 10 \mathrm{mM}$ EDTA, 1\% Triton X-100, $200 \mathrm{mM}$ sodium fluoride, and $4 \mathrm{mM}$ sodium orthovanadate as a protease inhibitor (pH 7.5). Immunoblotting was then performed with primary antibodies against NLRP3(1:500), COX-2 (Cayman Chemical, USA, 1:500), mPGES-1 (Cayman Chemical, USA, 1:500), and $\beta$-actin (1:1000), followed by adding HRP-labeled secondary antibodies. The blots were visualized using the Amersham ECL detection system (Amersham, Little Chalfont, UK). Densitometric analysis was performed using Quantity One software (BioRad).

\section{EIA assay}

The concentration of PGE2 in the medium was examined using the commercial EIA kits purchased from Cayman Chemical.

Apoptosis analysis

Annexin V-fluorescein isothiocyanate conjugated with propidium iodide staining

Following the treatment, mPTCs were collected in suspension by $0.25 \%$ trypsin- $0.02 \%$ EDTA and were washed with PBS. Then the cells were double stained with annexin V-fluorescein isothiocyanate and propidium iodide (Annexin V: FITC Apoptosis Detection Kit, BD Biosciences, San Diego, CA) according to the manufacturer's instructions. Quantification was performed by flow cytometry. There were 6 samples for each group.

TUNEL assay in cultured mPTCS

Apoptotic cell death was determined using TUNEL staining with an In Situ Cell Death Detection Kit (Roche Molecular
Table 1. Primer sequences for qRT-PCR

\begin{tabular}{|c|c|}
\hline Gene symbol & Primer sequences \\
\hline \multirow[t]{2}{*}{ GAPDH } & $5^{\prime}$ - GTCTTCACTACCATGGAGAAGG -3' \\
\hline & $5^{\prime}-$ TCATGGATGACCTTGGCCAG $-3^{\prime}$ \\
\hline \multirow[t]{2}{*}{ NLRP3 } & 5'-GTGGTGACCCTCTGTGAGGT-3' \\
\hline & 5'-TCTTCCTGGAGCGCTTCTAA-3' \\
\hline \multirow[t]{2}{*}{ mPGES1 } & $5^{\prime}-$ GGATGCGCTGAAACGTGGA - 3' \\
\hline & $5^{\prime}-$ CAGGAATGAGTACACGAAGCC - $3^{\prime}$ \\
\hline \multirow[t]{2}{*}{ mPGES2 } & $5^{\prime}-$ CCTCGACTTCCACTCCCTG - 3' \\
\hline & $5^{\prime}$ - TGAGGGCACTAATGATGACAGAG - 3' \\
\hline \multirow[t]{2}{*}{ cPGES } & 5'- TGTTTGCGAAAAGGAGAATCCG - 3' \\
\hline & $5^{\prime}$ - CCATGTGATCCATCATCTCAGAG - $3^{\prime}$ \\
\hline \multirow[t]{2}{*}{ COX1 } & $5^{\prime}$ - ATGAGTCGAAGGAGTCTCTCG - $3^{\prime}$ \\
\hline & $5^{\prime}$ - GCACGGATAGTAACAACAGGGA - $3^{\prime}$ \\
\hline \multirow[t]{2}{*}{$\mathrm{COX} 2$} & $5^{\prime}$ - AACCGTGGGGAATGTATGAG - 3' \\
\hline & 5'- GCAGGAAGGGGATGTTGTT - 3' \\
\hline \multirow[t]{2}{*}{ IL-1 $\beta$} & $5^{\prime}$ - CAAAAATGCCTCGTGCTGT - $3^{\prime}$ \\
\hline & 5'- GTGGGTGTGCCGTCTTTC - 3' \\
\hline \multirow[t]{2}{*}{ IL-18 } & $5^{\prime}$ - TGGCTGTGACCCTATCTGTG - $3^{\prime}$ \\
\hline & 5'- TCATCTTCСTTTTGGCAAGC - 3' \\
\hline \multirow[t]{2}{*}{ IL-6 } & $5^{\prime}$ - ATACCACCCACAACAGACCA - $3^{\prime}$ \\
\hline & $5^{\prime}-$ CTCCAGAAGACCAGAGCAGA - $3^{\prime}$ \\
\hline \multirow[t]{2}{*}{ ICAM-1 } & $5^{\prime}$ - GCCTTGGTAGAGGTGACTGAG - $3^{\prime}$ \\
\hline & $5^{\prime}$ - GACCGGAGCTGAAAAGTTGTA - 3' \\
\hline \multirow[t]{2}{*}{ KIM-1 } & $5^{\prime}$ - ATGAATCAGATTCAAGTCTTC - 3' \\
\hline & $5^{\prime}$ - TCTGGTTTGTGAGTCCATGTG - $3^{\prime}$ \\
\hline
\end{tabular}


Biochemicals, Mannheim, Germany) following the manufacturer's protocol. mPTCs undergoing apoptosis were detected by counterstaining with Hoechst 33258. The slides were examined by confocal microscopy. There were 6 samples for each group and 6 fields were randomly taken in each slide.

\section{Statistical analysis}

All data are presented as means \pm standard deviation (SD). The statistical analysis was performed using ANOVA followed by Bonferroni's test or unpaired Student's t-test with SPSS 13 statistical software. P $<0.05$ was considered significant.

\section{Results}

Inhibition of NLRP3 by siRNA approach blunted albumin-induced cell injury in mPTCS

Application of NLRP3 siRNA significantly reduced protein and mRNA expressions of NLRP3 in mPTCs (Fig. 1A-C). Interestingly, the tubular injury marker of KIM-1 was remarkably induced by albumin in dose- and time-dependent manners (Fig. 2A\&B), and

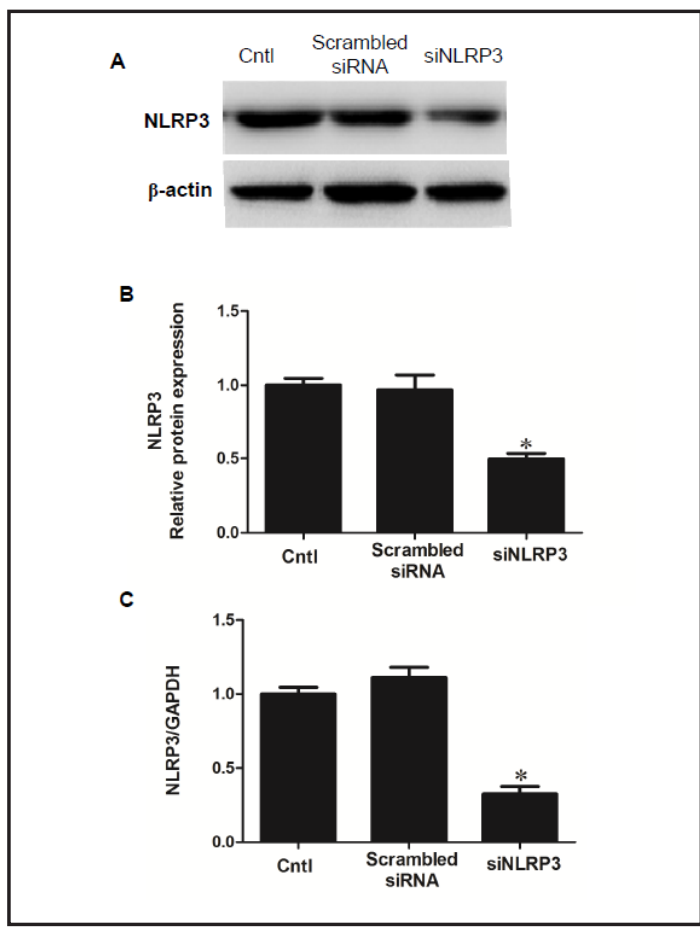

Fig. 1. Transfection of NLRP3 siRNA. (A) Western blots of NLRP3 after transfection of siNLRP3. Cells were transfected with siNLRP3 or scramble (Vehi) for $48 \mathrm{~h}$, and untreated cells were used as the control. (B) Desitometric analysis of NLRP3. (C) qRTPCR analysis of NLRP3 mRNA expression. Cells were transfected with siNLRP3 or scrambled siRNA for $24 \mathrm{~h}$, and untreated cells were used as the control. The values represent means \pm SD ( $n=6$ per group). * $\mathrm{P}<0.01$ vs. scrambled siRNA group. Cntl: treatment with transfection reagent alone.

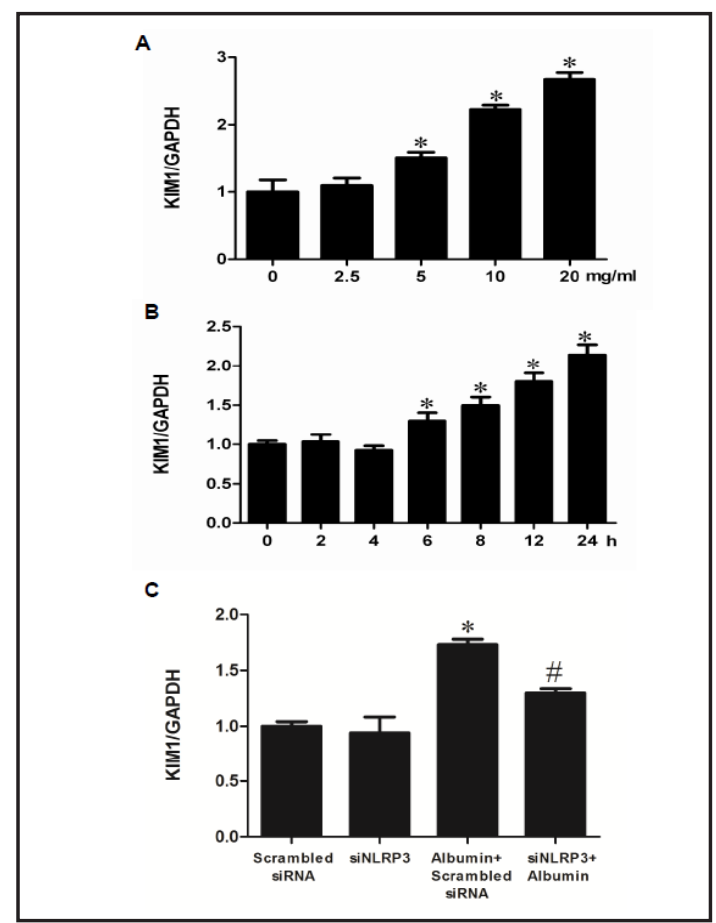

Fig. 2. NLRP3 siRNA blunted albumin-induced KIM1 expression. (A) qRT-PCR analysis of KIM-1 mRNA expression in mPTCs after treatment by different doses of albumin (0-20 mg/ml). (B) qRT-PCR analysis of KIM-1 mRNA expression in mPCTs following $10 \mathrm{mg} / \mathrm{ml}$ albumin treatment in a time course study. (C) qRT-PCR analysis of KIM-1 mRNA expression in mPTCs following $10 \mathrm{mg} / \mathrm{ml}$ albumin treatment with or without NLRP3 silencing. Confluent mPTCs were transfected with siNlrp3 or scrambled siRNA for $48 \mathrm{~h}$ and then incubated with albumin $(10 \mathrm{mg} / \mathrm{ml})$ for additional $24 \mathrm{~h}$. The values represent means \pm SD ( $\mathrm{n}=6$ per group). ${ }^{*} \mathrm{P}<0.01$ vs. scrambled siRNA group. ${ }^{\#} \mathrm{P}<0.01$ vs. Albumin + Scrambled siRNA group. 


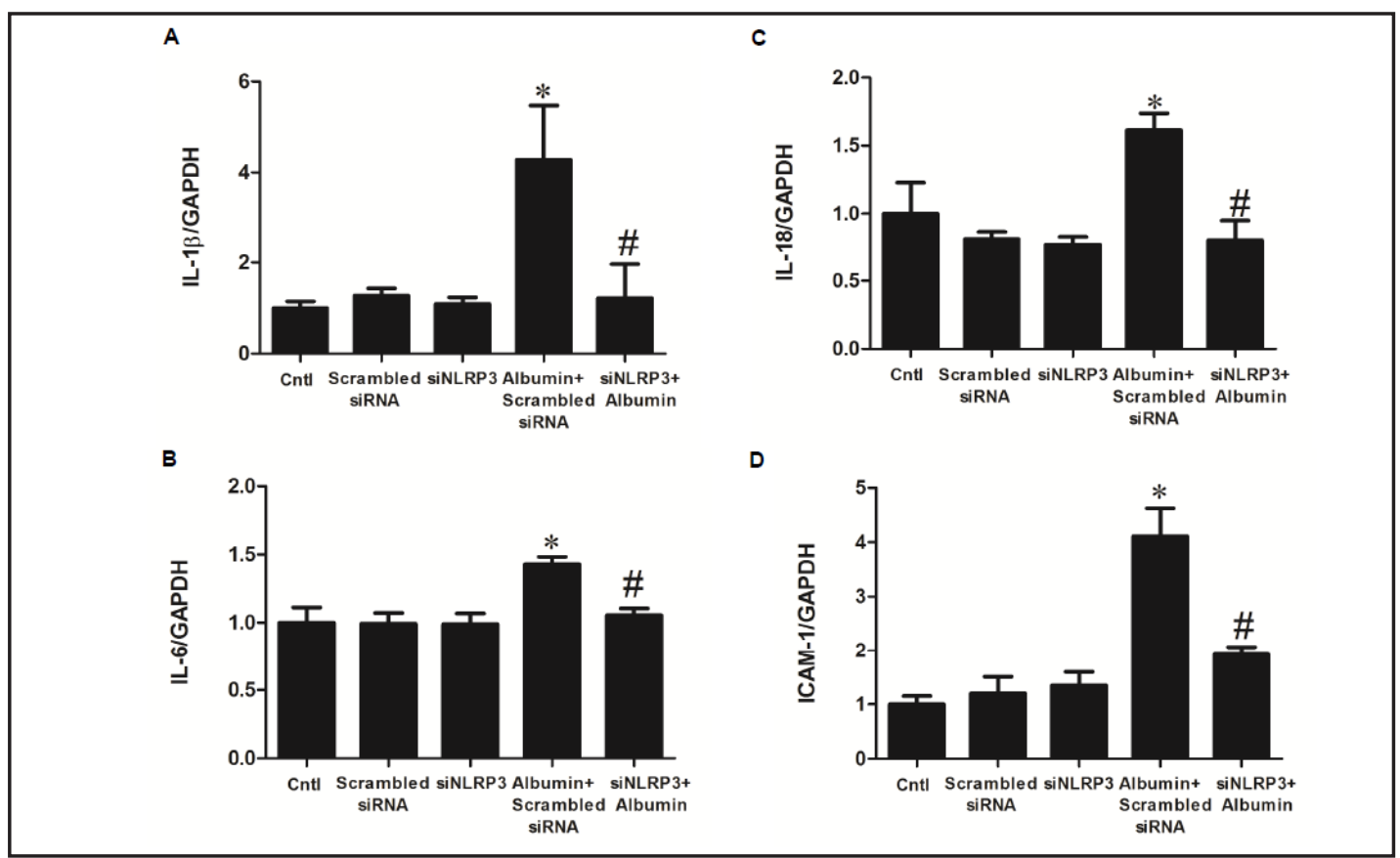

Fig. 3. NLRP3 silencing blunted albumin-induced over-expressions of inflammatory cytokines in mPCTs. mPTCs were transfected with siNlrp3 for $48 \mathrm{~h}$ and then incubated with albumin $(10 \mathrm{mg} / \mathrm{ml})$ for additional 24 h. (A) qRT-PCR analysis of IL-1ß. (B) qRT-PCR analysis of IL-18. (C) qRT-PCR analysis of IL-6. (D) qRT-PCR analysis of ICAM-1. The values are means \pm SD ( $n=6$ per group). ${ }^{*} \mathrm{P}<0.01$ vs. Scrambled siRNA group. ${ }^{\#} \mathrm{P}<$ 0.01 vs. Albumin + Scrambled siRNA group. Cntl: treatment with transfection reagent alone.

Fig. 4. NLRP3 silencing attenuated albumin-induced apoptosis in mPTCs. mPTCs were transfected with siNlrp3 for $48 \mathrm{~h}$ and then incubated with albumin (10 $\mathrm{mg} /$ $\mathrm{ml}$ ) for additional $24 \mathrm{~h}$. (A) Quantification of apoptotic cells by flow cytometry. (B) Representative photographs of double-fluorescence labelling of Hoechst nuclear staining (blue) and TUNEL (green). mPTCs were incubated with albumin at $10 \mathrm{mg} / \mathrm{ml}$ for $24 \mathrm{~h}$. The values represent means \pm SD $(n=6$ in each group). ${ }^{*} \mathrm{P}<0.01$ vs. Scrambled siRNA group. ${ }^{\#} \mathrm{P}<$ 0.01 vs. Albumin + Scrambled siRNA group. Cntl: treatment with transfection reagent alone.

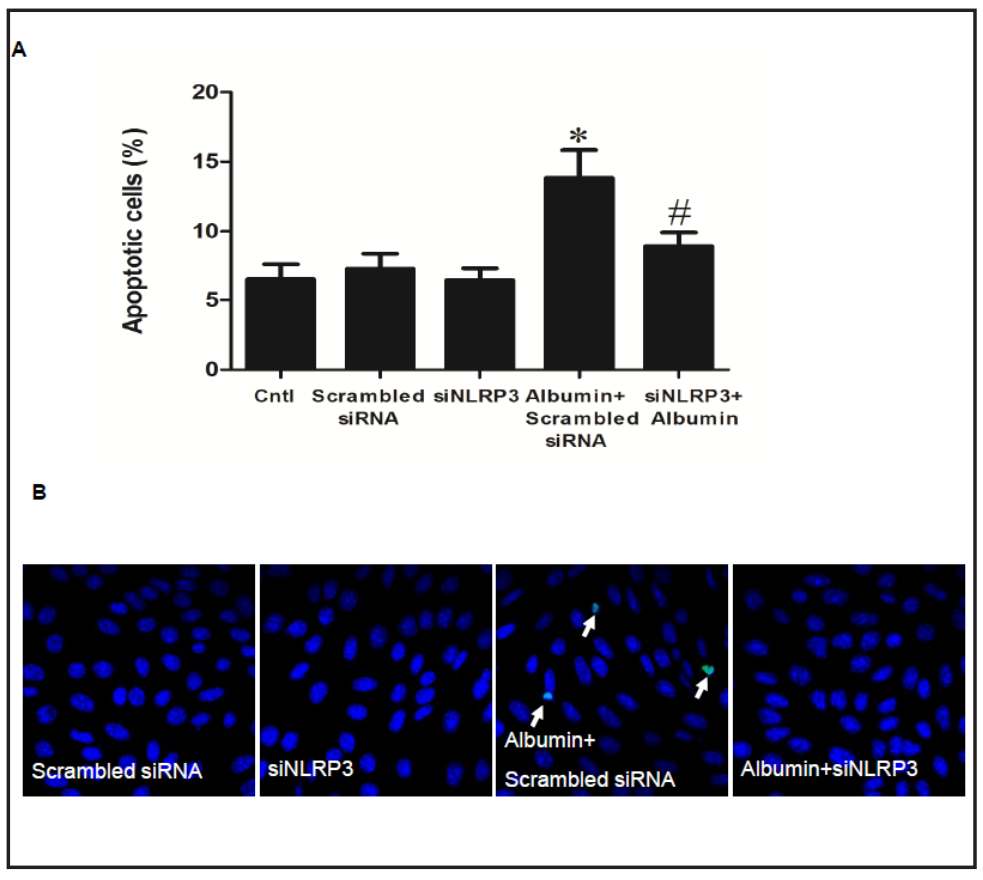

such an induction was significantly blunted by NLRP3 siRNA treatment (Fig. 2C). Meanwhile, the elevation of inflammatory cytokines of IL-1 $\beta$, IL-18, IL-6, and ICAM-1 following albumin treatment was markedly blocked by NLRP3 siRNA, as determined by qRT-PCR (Fig. 3AD). In line with the inhibition of KIM-1 and inflammatory cytokines, albumin-induced cell apoptosis was also attenuated by siNLRP3 (Fig. 4). 


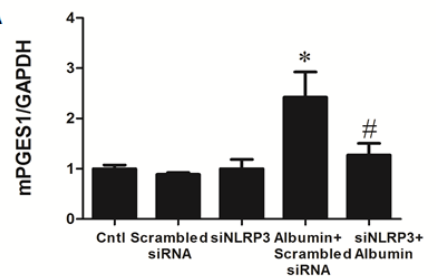

C

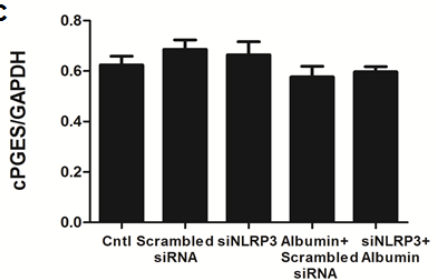

E

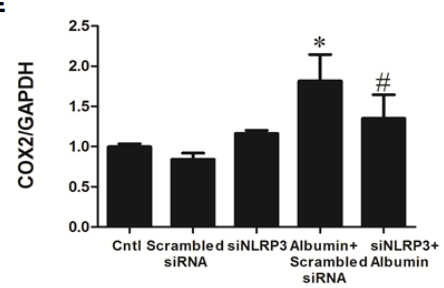

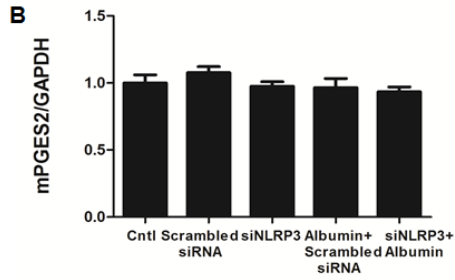

D

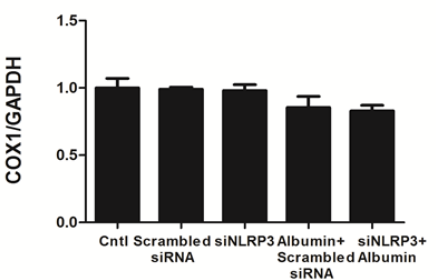

Fig. 5. NLRP3 silencing inhibited albumin-mediated upregulation of COX-2 and mPGES-1 mRNA expressions in mPTCs. mPTCs were transfected with siNlrp3 for $48 \mathrm{~h}$ and then incubated with albumin $(10 \mathrm{mg} / \mathrm{ml})$ for additional 24 h. (A) qRT-PCR analysis of mPGES-1. (B) qRT-PCR analysis of mPGES-2. (C) qRT-PCR analysis of cPGES. (D) qRT-PCR analysis of COX-1. (E) qRT-PCR analysis of COX-2. The values represent means \pm $\mathrm{SD}\left(\mathrm{n}=6\right.$ per group). ${ }^{*} \mathrm{P}<0.01$ vs. Scrambled siRNA group. ${ }^{\#} \mathrm{P}<0.01$ vs. Albumin + Scrambled siRNA group. Cntl: treatment with transfection reagent alone.

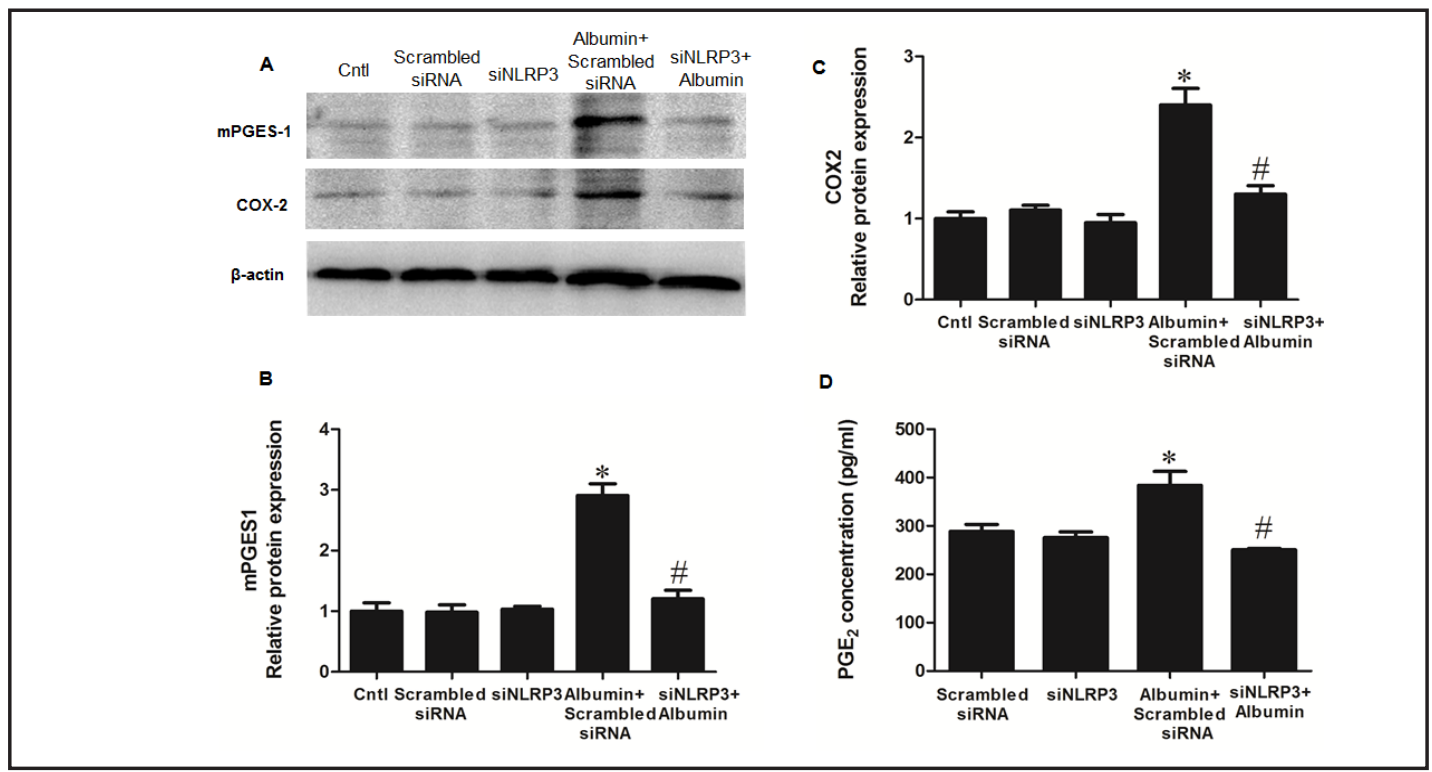

Fig. 6. NLRP3 silencing inhibited albumin-induced upregulation of COX-2 and mPGES-1 proteins and PGE2 secretion in mPTCs. mPTCs were transfected with siNlrp3 for $48 \mathrm{~h}$ and then incubated with albumin (10 $\mathrm{mg} / \mathrm{ml}$ ) for additional $48 \mathrm{~h}$. (A) Western blots of mPGES-1 and COX-2. (B) Densitometric analysis of mPGES-1. (C) Densitometric analysis of COX-2. (D) PGE2 secretion in cell culture medium. The values are means $\pm \mathrm{SD}$ ( $\mathrm{n}=6$ per group). ${ }^{*} \mathrm{P}<0.01$ vs. Scrambled siRNA group. ${ }^{*} \mathrm{P}<0.01$ vs. Albumin + Scrambled siRNA group. Cntl: treatment with transfection reagent alone.

\section{KARGER}




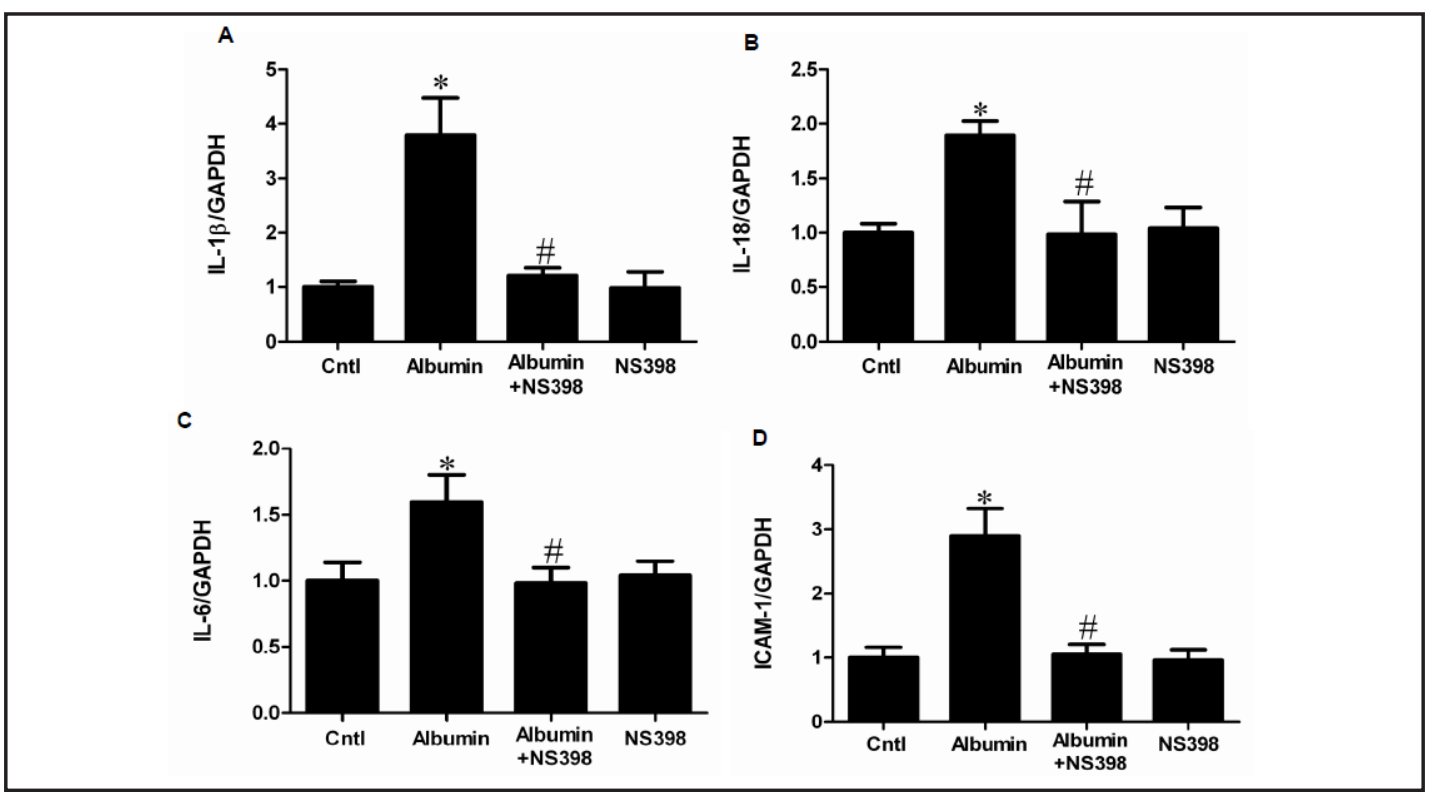

Fig. 7. Inhibition of COX-2 activity by NS398 reversed albumin-induced over-expressions of inflammatory cytokines in mPCTs. mPTCs were treated with NS398 for $30 \mathrm{~min}$ and then incubated with albumin (10 mg/ $\mathrm{ml}$ ) for additional $24 \mathrm{~h}$. (A) qRT-PCR analysis of IL-1ß. (B) qRT-PCR analysis of IL-18. (C) qRT-PCR analysis of IL-6. (D) qRT-PCR analysis of ICAM-1. The values are means \pm SD ( $\mathrm{n}=6$ per group). ${ }^{*} \mathrm{P}<0.01$ vs. control. ${ }^{\#} \mathrm{P}<0.01$ vs. albumin-treated mPTCs.

Inhibition of NLRP3 by siRNA approach blunted albumin-induced activation of COX-2/ mPGES-1/PGE2 cascade in mPTCS

After treating the mPTCs with albumin at the dose of $10 \mathrm{mg} / \mathrm{ml}$ for $24 \mathrm{~h}$, the mRNA expressions of COX-2 and mPGES-1, but not COX-1, mPGES-2, and CPGES, were selectively up-regulated as determined by qRT-PCR (Fig. 5A-E). By application of NLRP3 siRNA, albumin-induced upregulation of COX-2 and mPGES-1 mRNA expressions were significantly blunted (Fig. 5A\&E) without affecting COX-1 and other PGE2 synthases (Fig. 5B-D). By Western blotting, we further confirmed the induction of COX-2 and mPGES-1 at protein levels (Fig. 6A-C), which was remarkably blocked by NLRP3 silencing. (Fig.6A-C). In line with the activation of COX-2/mPGES1 pathway, the PGE2 release in the cell culture medium was also significantly elevated in response to the albumin treatment for $24 \mathrm{~h}$ (Fig. 6D). Such an increase of PGE2 was completely abolished by silencing NLRP3 (Fig. 6D).

Inhibition of COX-2 abolished albumin-stimulated inflammatory response and cell injury in $\mathrm{MPTCS}$

Following the activation of NLRP3 inflammasome by albumin, the mRNA levels of IL-1 $\beta$, IL-18, IL-6, and ICAM-1 were all stimulated in mPTCs (Fig. 7A-D). Inhibition of COX-2 by a specific COX-2 inhibitor of NS398 robustly abolished the induction of these inflammatory cytokines (Fig. 7A-D). At the same time, albumin-induced KIM-1 expression and cell apoptosis were also diminished by NS398 in parallel with reduced PGE2 production (Fig. 8AD). These novel findings highly suggested that COX-2/mPGES-1/PGE2 cascade served as a downstream signaling of NLRP3 inflammasome in albumin-induced renal tubular cell injury.

\section{Discussion}

Proteinuria is not only a common phenomenon in CKD patients but also a direct insult promoting the renal injury $[2,25,26]$. By now, there is no effective target for treating proteinuria-associated kidney injury possibly due to the incomplete understanding of 
A

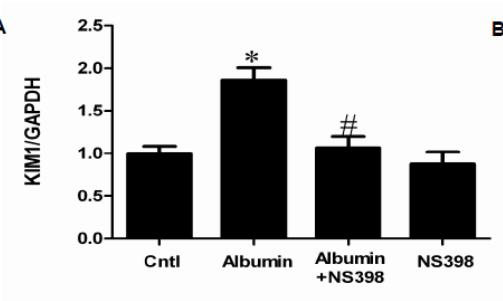

c

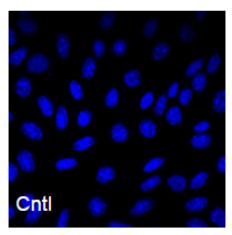

B
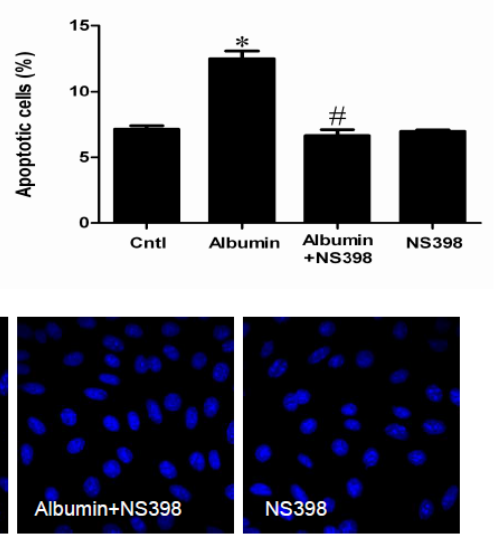

$\mathrm{D}$

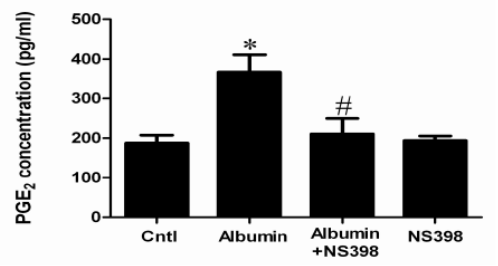

Fig. 8. Effects of COX-2 inhibition on albumin-induced cell injury and PGE2 production in mPCTs. mPTCs were treated with NS398 for $30 \mathrm{~min}$ and then incubated with albumin (10 mg/ml) for additional $24 \mathrm{~h}$. (A) qRT-PCR analysis of KIM-1 mRNA expression. (B) Quantification of apoptotic cells by flow cytometry. (C) Representative photographs of double-fluorescence labelling of Hoechst nuclear staining (blue) and TUNEL (green). (D) EIA assay of medium PGE2 concentration. Confluent mPTCs were incubated with albumin $24 \mathrm{~h}$ following NS398 treatment and the medium was collected to detect PGE2 by EIA. The values are means \pm SD ( $\mathrm{n}=6$ per group). ${ }^{*} \mathrm{P}<0.01$ vs. control. ${ }^{*} \mathrm{P}<0.01$ vs. albumin-treated mPTCs.

the mechanisms mediating the proteinuria-induced tubular damage. Inflammation is a common feature of various CKDs and is highly involved in the development and progression of CKD. NLRP3 inflammasome is one of the best characterized inflammasomes [27-30]. Recently, accumulating evidence demonstrated that NLRP3 inflammasome contributes to the CKDs $[3,31,32]$ and can be activated by the albumin in human proximal tubule cells [4]. In present study, by blocking NLRP3 via a siRNA strategy, the tubular injury marker of KIM-1, cell apoptosis and inflammatory cytokines were all suppressed, suggesting a critical role of NLRP3 in mediating albumin-caused tubular cell injury possibly via augmenting the inflammatory response.

Among the inflammatory mediators, PGE2 has a known role in mediating the inflammatory response in various kidney injuries [11, 12, 33, 34]. Blockade of PGE2 production by inhibiting its synthetic enzymes of COX-2 or mPGES-1 could improve many kidney diseases in animals [19, 24, 35-37], suggesting a pathogenic role of COX-2/mPGES-1/ PGE2 pathway in kidney injury. In the present study, we found that albumin significantly up-regulated COX-2/mPGES-1/PGE2 cascade in mPTCs. By blocking NLRP3 via a siRNA approach, the induction of this prostaglandin cascade was largely normalized, indicating that NLRP3 inflammasome could be responsible for mediating the albumin effect on activating COX-2/mPGES-1/PGE2 cascade.

To evaluate whether activation of COX-2/mPGES-1/PGE2 signaling contributes albumininduced cell injury, a specific COX-2 inhibitor of NS398 was applied. Strikingly, inhibition of COX-2 reversed KIM-1 induction and cell apoptosis caused by albumin challenge. Meantime, the PGE2 release was also blunted. These results highly supported that COX-2/PGE2 cascade served as a detrimental factor in albumin-induced tubular cell injury.

\section{KARGER}




\section{Cellular Physiology Cell Physiol Biochem 2017;42:797-807

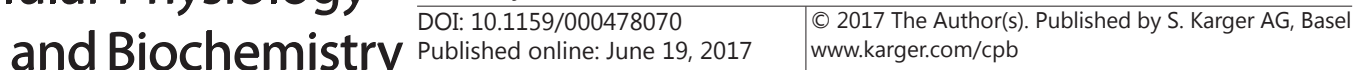

Among three PGE2 synthases, only mPGES-1 has been proved to have the ability in producing PGE2 in vivo $[14,21]$, and is thought as the most promising target of next generation of anti-inflammatory drugs [38, 39]. As a downstream enzyme of COX, it is possible that the mPGES-1 inhibitors may preserve less adverse effects than the COX inhibitors in treating the inflammatory diseases. Proteinuria is known as an insult of renal tubulointerstitial inflammation resulting in the subsequent renal lesions in morphology and function [25]. In agreement with this notion, we observed an obvious elevation of mPGES- 1 at mRNA and protein levels in this experimental setting, suggesting that mPGES-1-derived PGE2 might be a pathogenic contributor of proteinuria-associated renal injury.

In summary, the present study demonstrated a critical role of NLRP3 in mediating the albumin effect on activating COX-2/mPGES-1/PGE2 cascade in renal tubular cells. COX-2/ mPGES-1/PGE2 cascade activation could contribute to albumin-induced tubular cell injury. By now, there are no effective clinical strategies in treating proteinuria-related kidney injury. These findings could shed new light on the understanding and treatment of proteinuriacaused renal damage.

\section{Acknowledgement}

This work was supported by grants from the National Key Research and Development Program (no. 2016YFC0906103), the National Natural Science Foundation of China (Nos. 81325004, 81300591, 81270797, 81670647, 81570616, and 81270785), the Natural Science Foundation of Jiangsu Province (No. BK2012001), and the Program for New Century Excellent Talents in University (No. NCET-12-0738).

\section{Disclosure Statement}

There is no conflict of interests to disclose.

\section{References}

1 Kazancioglu R: Risk factors for chronic kidney disease: an update. Kidney Int Suppl (2011) 2013;3:368371.

2 Burton C, Harris KP: The role of proteinuria in the progression of chronic renal failure. Am J Kidney Dis 1996;27:765-775.

-3 Vilaysane A, Chun J, Seamone ME, Wang W, Chin R, Hirota S, Li Y, Clark SA, Tschopp J, Trpkov K, Hemmelgarn BR, Beck PL, Muruve DA: The NLRP3 inflammasome promotes renal inflammation and contributes to CKD. J Am Soc Nephrol 2010;21:1732-1744.

4 Fang L, Xie D, Wu X, Cao H, Su W, Yang J: Involvement of endoplasmic reticulum stress in albuminuria induced inflammasome activation in renal proximal tubular cells. PLoS One 2013;8:e72344.

-5 Zhuang Y, Jia Z, Hu C, Ding G, Zhang X, Zhang Y, Yang G, Rohatgi R, Huang S, He JC, Zhang A: Albuminuria confers renal resistance to loop diuretics via the stimulation of NLRP3 inflammasome/prostaglandin signaling in thick ascending limb. Oncotarget DOI:10.18632/oncotarget.10257.

-6 Nasrallah R, Clark J, Hebert RL: Prostaglandins in the kidney: developments since Y2K. Clin Sci (Lond) 2007;113:297-311.

-7 Stokes JB, Kokko JP: Inhibition of sodium transport by prostaglandin E2 across the isolated, perfused rabbit collecting tubule. J Clin Invest 1977;59:1099-1104.

-8 Stokes JB: Effect of prostaglandin E2 on chloride transport across the rabbit thick ascending limb of Henle. Selective inhibitions of the medullary portion. J Clin Invest 1979;64:495-502.

-9 Stokes JB: Integrated actions of renal medullary prostaglandins in the control of water excretion. Am J Physiol 1981;240:F471-480. 


\section{Cellular Physiology Cell Physiol Biochem 2017;42:797-807 \begin{tabular}{ll|l} 
DOI: 10.1159/000478070 & $\begin{array}{l}\text { O 2017 The Author(s). Published by S. Karger AG, Basel } \\
\text { www.karger.com/cpb }\end{array}$
\end{tabular}

-10 Guan Y, Zhang Y, Breyer RM, Fowler B, Davis L, Hebert RL, Breyer MD: Prostaglandin E2 inhibits renal collecting duct $\mathrm{Na}+$ absorption by activating the EP1 receptor. J Clin Invest 1998;102:194-201.

11 Mohamed R, Jayakumar C, Ranganathan PV, Ganapathy V, Ramesh G: Kidney proximal tubular epithelialspecific overexpression of netrin-1 suppresses inflammation and albuminuria through suppression of COX2-mediated PGE2 production in streptozotocin-induced diabetic mice. Am J Pathol 2012;181:1991-2002.

-12 Ranganathan PV, Jayakumar C, Mohamed R, Dong Z, Ramesh G: Netrin-1 regulates the inflammatory response of neutrophils and macrophages, and suppresses ischemic acute kidney injury by inhibiting COX2-mediated PGE2 production. Kidney Int 2013;83:1087-1098.

-13 Ren Y, D'Ambrosio MA, Garvin JL, Wang H, Carretero OA: Prostaglandin E2 mediates connecting tubule glomerular feedback. Hypertension 2013;62:1123-1128.

14 Murakami M, Naraba H, Tanioka T, Semmyo N, Nakatani Y, Kojima F, Ikeda T, Fueki M, Ueno A, Oh S, Kudo I: Regulation of prostaglandin E2 biosynthesis by inducible membrane-associated prostaglandin E2 synthase that acts in concert with cyclooxygenase-2. J Biol Chem 2000;275:32783-32792.

15 Crofford LJ: COX-1 and COX-2 tissue expression: implications and predictions. J Rheumatol Suppl 1997;49:15-19.

16 Smith WL, Garavito RM, DeWitt DL: Prostaglandin endoperoxide H synthases (cyclooxygenases)-1 and -2. J Biol Chem 1996;271:33157-33160.

17 Breyer MD, Harris RC: Cyclooxygenase 2 and the kidney. Curr Opin Nephrol Hypertens 2001;10:89-98.

18 Norregaard R, Kwon TH, Frokiaer J: Physiology and pathophysiology of cyclooxygenase-2 and prostaglandin E2 in the kidney. Kidney Res Clin Pract 2015;34:194-200.

19 Jia Z, Wang N, Aoyagi T, Wang H, Liu H, Yang T: Amelioration of cisplatin nephrotoxicity by genetic or pharmacologic blockade of prostaglandin synthesis. Kidney Int 2011;79:77-88.

-20 Jia Z, Zhang Y, Ding G, Heiney KM, Huang S, Zhang A: Role of COX-2/mPGES-1/prostaglandin E2 cascade in kidney injury. Mediators Inflamm 2015;2015:147894.

-21 Inada M, Matsumoto C, Uematsu S, Akira S, Miyaura C: Membrane-bound prostaglandin E synthase-1mediated prostaglandin E2 production by osteoblast plays a critical role in lipopolysaccharide-induced bone loss associated with inflammation. J Immunol 2006;177:1879-1885.

-22 Jania LA, Chandrasekharan S, Backlund MG, Foley NA, Snouwaert J, Wang IM, Clark P, Audoly LP, Koller BH: Microsomal prostaglandin E synthase-2 is not essential for in vivo prostaglandin E2 biosynthesis. Prostaglandins Other Lipid Mediat 2009;88:73-81.

23 Lovgren AK, Kovarova M, Koller BH: cPGES/p23 is required for glucocorticoid receptor function and embryonic growth but not prostaglandin E2 synthesis. Mol Cell Biol 2007;27:4416-4430.

24 Jia Z, Wang H, Yang T: Microsomal prostaglandin E synthase 1 deletion retards renal disease progression but exacerbates anemia in mice with renal mass reduction. Hypertension 2012;59:122-128.

25 Eddy AA: Proteinuria and interstitial injury. Nephrol Dial Transplant 2004;19:277-281.

$26 \mathrm{Hu}$ J, Zhu Q Li PL, Wang W, Yi F, Li N: Stem cell conditioned culture media attenuated albumin-induced epithelial-mesenchymal transition in renal tubular cells. Cell Physiol Biochem 2015;35:1719-1728.

27 Huang Z, Zhuang X, Xie C, Hu X, Dong X, Guo Y, Li S, Liao X: Exogenous Hydrogen Sulfide Attenuates High Glucose-Induced Cardiotoxicity by Inhibiting NLRP3 Inflammasome Activation by Suppressing TLR4/NFкB Pathway in H9c2 Cells. Cell Physiol Biochem 2016;40:1578-1590.

-28 Liu W, Zhang X, Zhao M, Zhang X, Chi J, Liu Y, Lin F, Fu Y, Ma D, Yin X: Activation in M1 but not M2 Macrophages Contributes to Cardiac Remodeling after Myocardial Infarction in Rats: a Critical Role of the Calcium Sensing Receptor/NRLP3 Inflammasome. Cell Physiol Biochem 2015;35:2483-2500.

29 Wang P, Ren D, Chen Y, Jiang M, Wang R, Wang YG: Effect of sodium alginate addition to resveratrol on acute gouty arthritis. Cell Physiol Biochem 2015;36:201-207.

-30 Schroder K, Tschopp J: The inflammasomes. Cell 2010;140:821-832.

-31 Bakker PJ, Butter LM, Kors L, Teske GJ, Aten J, Sutterwala FS, Florquin S, Leemans JC: Nlrp3 is a key modulator of diet-induced nephropathy and renal cholesterol accumulation. Kidney Int 2014;5:1112-1122

-32 Zhao J, Wang H, Dai C, Zhang H, Huang Y, Wang S, Gaskin F, Yang N, Fu SM: P2X7 blockade attenuates murine lupus nephritis by inhibiting activation of the NLRP3/ASC/caspase 1 pathway. Arthritis Rheum 2013;65:3176-3185. 


\section{Cellular Physiology Cell Physiol Biochem 2017;42:797-807

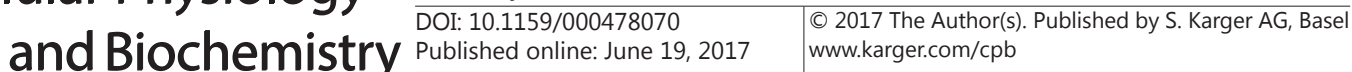

33 Nakagawa N, Yuhki K, Kawabe J, Fujino T, Takahata O, Kabara M, Abe K, Kojima F, Kashiwagi H, Hasebe N, Kikuchi K, Sugimoto Y, Narumiya S, Ushikubi F: The intrinsic prostaglandin E2-EP4 system of the renal tubular epithelium limits the development of tubulointerstitial fibrosis in mice. Kidney Int 2012;82:158171.

34 Kvirkvelia N, McMenamin M, Chaudhary K, Bartoli M, Madaio MP: Prostaglandin E2 promotes cellular recovery from established nephrotoxic serum nephritis in mice, prosurvival, and regenerative effects on glomerular cells. Am J Physiol Renal Physiol 2013;304:F463-470.

35 Jia Z, Sun Y, Liu S, Liu Y, Yang T: COX-2 but Not mPGES-1 Contributes to Renal PGE2 Induction and Diabetic Proteinuria in Mice with Type-1 Diabetes. PLoS One 2014;9:e93182.

36 Cheng H, Wang S, Jo YI, Hao CM, Zhang M, Fan X, Kennedy C, Breyer MD, Moeckel GW, Harris RC: Overexpression of cyclooxygenase-2 predisposes to podocyte injury. J Am Soc Nephrol 2007;18:551-559.

37 Murakami M, Kudo I: Prostaglandin E synthase: a novel drug target for inflammation and cancer. Curr Pharm Des 2006;12:943-954.

38 Dallaporta M, Pecchi E, Thirion S, Jean A, Troadec JD: Toward the management of inflammation: recent developments of mPGES-1 inhibitors. Recent Pat CNS Drug Discov 2010;5:70-80.

-39 Chang HH, Meuillet EJ: Identification and development of mPGES-1 inhibitors: where we are at? Future Med Chem 2011;3:1909-1934. 